(2) Open Access Full Text Article

\title{
Posteroanterior chest $X$-ray for the diagnosis of pneumothorax: methods, usage, and resolution
}

This article was published in the following Dove Press journal:

Reports in Medical Imaging

27 August 2010

Number of times this article has been viewed

\author{
Denise Rossato Silva \\ Sandra Jungblut Schuh \\ Paulo de Tarso Roth Dalcin \\ Universidade Federal do Rio Grande \\ do Sul, Porto Alegre-RS, Brazil
}

\begin{abstract}
Most pneumothoraces are demonstrated on fully inspired erect posteroanterior (PA) chest X-ray (CXR). Expiratory films may have a role in the clinical management of patients with a small respiratory reserve in whom pneumothorax is suspected and not demonstrated on the inspiratory film. PA CXR can be used for the diagnosis of spontaneous and nonspontaneous pneumothoraces. When digital radiography is used, for most authors, a $2.5-1 \mathrm{p} / \mathrm{mm}$ spatial resolution is satisfactory to detect a pneumothorax.
\end{abstract}

Keywords: radiography, computed tomography, pneumothorax, posteroanterior chest X-ray

\section{Introduction}

A pneumothorax is defined as the presence of gas or air from any source in the pleural cavity. The early and accurate diagnosis of pneumothorax is essential in preventing respiratory compromise and potential death. Most pneumothoraces are demonstrated on fully inspired erect posteroanterior (PA) chest X-ray (CXR). The radiographic diagnosis of a pneumothorax on a PA CXR relies on identification of a visceral pleural line separated from the parietal pleura by a radiolucent airspace. Pulmonary vessels are followed to the visceral pleural line, but not beyond. ${ }^{1}$ In this review, we discuss the methods, usage, and resolution of PA CXR in the diagnosis of pneumothorax.

\section{Methods}

In $\mathrm{CXR}$, the most common views are PA, anteroposterior (AP), and lateral. In a PA view, the X-ray source is positioned so that X-rays enter through the posterior (back) aspect of the chest and exit out of the anterior (front) aspect where they are detected. This view is done with the subject's chest up against the film holder or detector plate. The X-ray tube is behind the patient, and X-ray beam passes in from the back and exits out from the front of the chest. In AP views, the positions of the X-ray source and detector are reversed; X-rays enter through the anterior aspect and exit through the posterior aspect of the chest. AP CXR are harder to interpret than PA X-rays and are, therefore, generally reserved for situations where it is difficult for the patient to obtain a normal CXR such as when the patient cannot get out of bed. In this situation, mobile X-ray equipment is used to obtain a lying down CXR (known as a "supine film"). As a result, most supine films are also AP. For interpretative purposes, the main difference is that the heart will be more magnified on the AP projection. Also, small pneumothoraces will go to the anterior pleural surface and will easily be missed. Lateral views of the chest are obtained in a similar fashion as the PA views; except that in the lateral view, the patient stands with the left arm raised and the left side of the chest pressed against a flat surface. ${ }^{2}$
Correspondence: Denise Rossato Silva Rua São Manoel, 1584/606, Bairro Santana, Porto Alegre-RS, Brazil

Tel +555132195723

Fax +55 5I 33598001

Email denise.rossato@terra.com.br 
In the lateral view, because of the lack of composite shadows, small volumes of free air are readily demonstrated parallel to the chest wall, with sensitivities similar to those of computed tomography $(\mathrm{CT})$. $^{3}$

If there is diagnostic doubt as to the presence of a pneumothorax, an expiratory or lateral decubitus film could be taken. The rationale to request an expiratory CXR is that the volume of air in the pleural cavity is relatively greater in relation to the volume of lung so that the pleural separation renders the visceral surface more clearly visible. ${ }^{4}$ Decubitus radiography performed with the suspected side nondependent is usually reserved for patients who cannot undergo radiography in the erect position. In the lateral decubitus position, because of the lack of composite shadows, small volumes of free air are readily demonstrated parallel to the chest wall. ${ }^{3}$ However, in a study that compared the detectability of pneumothorax on expiratory, upright CXR with that on expiratory, lateral decubitus CXR obtained with the suspected side up, the authors found that radiologists detect pneumothorax more frequently on standard expiratory, upright CXR than on expiratory, decubitus CXR. ${ }^{5}$

Some authors have suggested that an expiratory CXR is more sensitive than an inspiratory CXR although based on no well-controlled studies. ${ }^{1,4}$ However, other studies have questioned the routine use of expiratory CXR since they double the cost of the investigation and the radiation dose and may give no further information than an inspiratory film alone. Less than $4 \%$ of pneumothoraces were not seen on inspiratory chest radiographs. ${ }^{6-8}$ On the other hand, expiratory CXR alone hinder interpretation of the remainder of the chest, creating false-positive opacities. Expiratory films may have a role in the clinical management of patients with a small respiratory reserve in whom a pneumothorax is suspected and not demonstrated on the inspiratory film. ${ }^{6}$

It is well known that size of pneumothorax is an important determinant of treatment. For the British Thoracic Society, a "small" is, therefore, regarded as a pneumothorax of less than $2 \mathrm{~cm}$ and "large" as a pneumothorax of greater than $2 \mathrm{~cm} .{ }^{9}$ The American College of Chest Physicians consider small pneumothoraces are those with less than 3-cm apex-to-cupola distance and large pneumothoraces are those with greater than or equal to 3 -cm apex-to-cupola distance. ${ }^{10}$ The gold standard for determining the size of a pneumothorax is CT volume measurements. ${ }^{11}$ The most commonly used objective method for estimating pneumothorax size is the Rhea method. ${ }^{12}$ This method uses the average of the interpleural distances, which is obtained from three linear measurements: at the maximum apical interpleural distance, midpoint of the upper half of the lung, and midpoint of the lower half of the lung on an erect PA CXR to estimate pneumothorax size in percent using a nomogram. ${ }^{12}$ In a study that has compared the Rhea method with CT-derived Collins method, ${ }^{13}$ the Rhea method was acceptably accurate for smaller pneumothoraces but may significantly underestimate the size of larger pneumothoraces. ${ }^{14}$

Conventional imaging has been undergoing a transition to the digital imaging because of the lower exposure dosage and the advantages in terms of image processing, transfer, and storage. A key feature of digital imaging is the inherent separation of image acquisition and display. Digitally acquired images can be processed in order to correct accidental overexposure or underexposure, or to enhance diagnostically relevant information before display. ${ }^{15}$ Digital imaging can be divided into two categories: computed radiography (CR) and digital radiography (DR). CR uses a photostimulable storage phosphor that stores the latent image with subsequent processing using a stimulating laser beam and can be easily adapted to a cassette-based system analogous to that used in screen-film radiography. DR is used to describe a digital $\mathrm{X}$-ray imaging system that reads the transmitted X-ray signal immediately after exposure with the detector in place. ${ }^{16}$

Although most pneumothoraces are diagnosed on CXR, CT remains the gold standard for the diagnosis of pneumothorax. CT scanning is more sensitive than a CXR at detecting pneumothorax, with $25 \%-40 \%$ of postbiopsy pneumothoraces noted on CT not detectable on a CXR.${ }^{17}$ However, CT scanning is generally not necessary unless abnormalities are noted on the plain chest radiograph that requires further evaluation or aberrant chest tube placement is suspected. ${ }^{9}$ High-resolution CT may also be helpful when underlying parenchymal lung disease is suspected but not clearly identified by a chest radiograph. ${ }^{9,18}$ One of the main indications for CT is to distinguish an emphysematous bulla from a pneumothorax, which can be difficult on standard radiographs. In patients with severe emphysema, the pleural line may be difficult to visualize because the lung appears hyperlucent, resulting in minimal difference in the radiodensity of the lung and the pneumothorax. In general, the pleural line associated with a pneumothorax is convex relative to the lateral chest wall, whereas the pleural line associated with a large bulla is usually concave relative to the lateral chest wall. ${ }^{19}$

CT often detects pneumothoraces that were not diagnosed on chest radiograph, which are called occult pneumothoraces. The incidence of occult pneumothoraces is approximately $5 \%$ in trauma patients, but reaches $15 \%$ among patients undergoing $\mathrm{CT} .{ }^{20-22} \mathrm{CT}$ scanning provides greater sensitivity than CXR in diagnosing small pneumothoraces in patients 
with trauma..$^{23,24}$ In the intensive care unit, approximately $30 \%-50 \%$ of pneumothoraces can be missed on a supine film. ${ }^{21,25}$ The importance of detection of a small pneumothorax is that, although they can be treated conservatively, some patients may experience progression of pneumothorax under positive pressure ventilation. ${ }^{26} \mathrm{CT}$ guidance may also be used for drainage of loculated pneumothoraces. ${ }^{25}$

\section{Radiographic signs of pneumothorax}

The radiographic appearance of pneumothorax depends on the radiographic projection, the patient's position, and the presence or absence of pleural adhesion and subsequent loculation. ${ }^{27}$

In the upright patient, air increases in the pleural space and separates the lung from the chest wall, allowing the visceral pleural line to become visible as a thin curvilinear opacity between vessel-containing lung and the avascular pneumothorax space. The pleural line remains fairly parallel to the chest wall. Figures 1 and 2 show examples of pneumothoraces. Curvilinear shadows projected over the lung apex that may mimic the visible visceral pleural line of a pneumothorax include vascular lines, tubes, clothing, bedding, hair, scapulae, skin folds, and the walls of bullae and cavities. Cysts, bullae, and cavities usually have inner margins that are concave to the chest wall rather than convex. ${ }^{27}$

In the supine patient, the highest part of the chest cavity lies anteriorly or anteromedially at the base near the

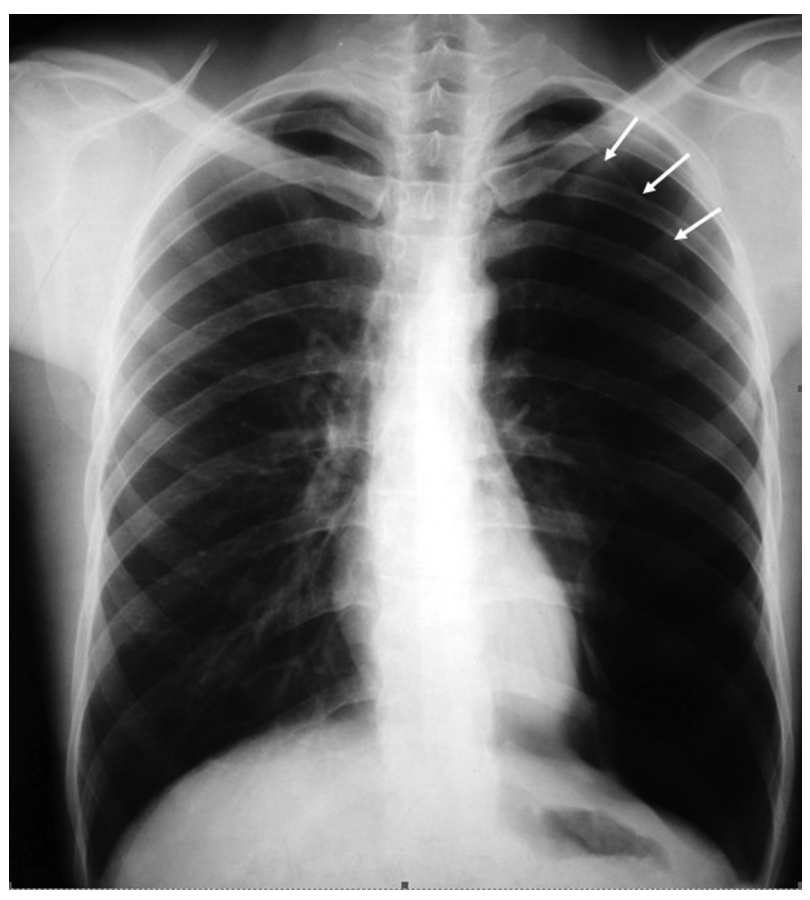

Figure I A thin line caused by the visceral pleura is seen separated from the lateral chest wall (arrows). Notice that no pulmonary vessels are seen beyond this line and that the line is curved.

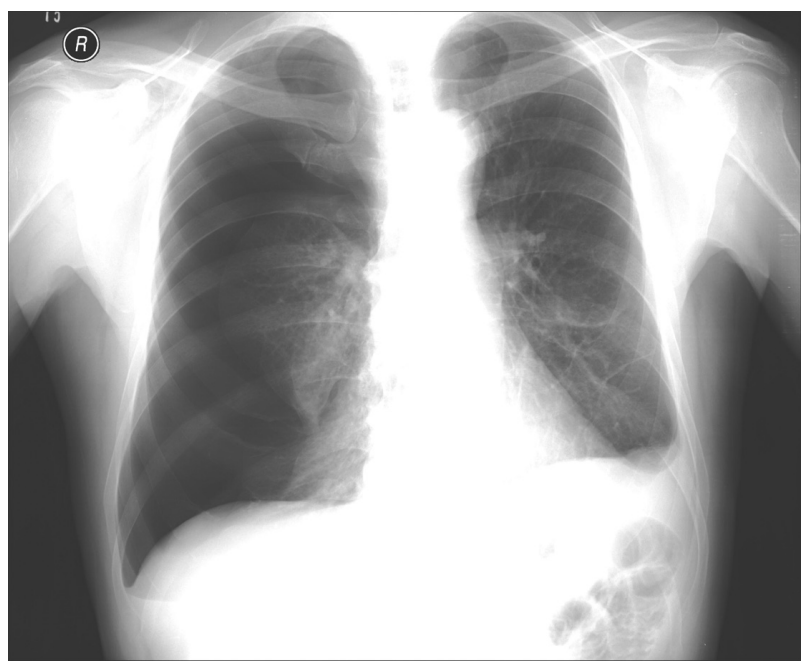

Figure 2 On a posteroanterior chest X-ray, the right hemithorax is very dark or lucent because the right lung has collapsed almost completely.

diaphragm, and free pleural air increases to this region. If the pneumothorax is small or moderate in size, the lung is not separated from the chest wall laterally or at the apex and, therefore, the pneumothorax may not be appreciated. Radiologic signs of a large tension pneumothorax include contralateral displacement of the mediastinum, inferior displacement of the diaphragm, hyperlucent hemithorax, and ipsilateral collapse of the lung. Signs of pneumothorax in a supine patient include relatively increased lucency of the involved hemithorax; increased sharpness of the adjacent mediastinal margin and diaphragm; deep, sometimes tongue like, costophrenic sulcus; visualization of the anterior costophrenic sulcus; increased sharpness of the cardiac borders; visualization of the inferior edge of the collapsed lung above the diaphragm; and depression of the ipsilateral hemidiaphragm. ${ }^{27}$

\section{Usage}

PA CXR can be used for the diagnosis of spontaneous and nonspontaneous pneumothoraces. Spontaneous pneumothorax, which occurs without an obvious precipitating event, can be divided into primary spontaneous pneumothorax (PSP) and secondary spontaneous pneumothorax (SSP). PSP occurs in patients without pre-existing clinically apparent lung disease, whereas SSP is found in those with underlying lung disease such as chronic obstructive pulmonary disease. Nonspontaneous pneumothorax can be subdivided into iatrogenic and noniatrogenic traumatic cases. Noniatrogenic pneumothoraces usually result from trauma, whereas iatrogenic pneumothoraces result from medical interventions. ${ }^{10}$ Chest CT scans are not routinely indicated in patients with PSP since there is no close correlation between the presence of subpleural blebs and the recurrence of pneumothorax..$^{28,29}$ 
In patients with penetrating trauma, the frequency of occult pneumothoraces is approximately $17 \%$, which may be reduced by using upright chest radiography. ${ }^{30}$ Although erect chest radiography is superior to supine chest radiography for detecting pneumothoraces (sensitivities of $92 \%$ and $50 \%$, respectively), it is not possible to attain upright views in all patients with blunt or even penetrating trauma ${ }^{23,31}$ because of competing concerns, such as cervical spine precautions, hemodynamic instability, immobilization of orthopedic injuries, ongoing resuscitation, and decreased level of consciousness. ${ }^{32} \mathrm{CT}$ is the best choice for diagnosing pneumothorax in the supine trauma patient. ${ }^{11}$

The clinical utility of a PA CXR after thoracocentesis has been evaluated in some studies. In a prospective cohort study, conducted in a tertiary care teaching hospital, patients clinically stable, who have not previously received chest irradiation, had only one pass at thoracocentesis attempted without the aspiration of any air, and no operator suspicion of pneumothorax have a low risk for pneumothorax (approximately 1\%) with minimal consequences to justify the avoidance of about $60 \%$ of chest radiographies obtained after thoracocentesis..$^{33}$ In other study, retrospective and in an outpatient setting, it was identified that postthoracocentesis CXR should be limited to patients with symptoms indicative of thoracocentesis-induced pneumothorax. ${ }^{34}$

Transthoracic sonography (TS) has been used as a diagnostic tool in pneumothorax and hydropneumothorax. ${ }^{35-37}$ In a study for detection of pneumothorax after transthoracic sonographically guided lung biopsy, ${ }^{38}$ TS was as effective as PA CXR. However, TS is not considered a reliable tool for estimating the size of pneumothorax. ${ }^{32,39}$ Despite the high sensitivity, specificity, and accuracy of TS, PA CXR may still be useful to assess pneumothorax extension and when any discrepancy between TS results and clinical presentation exists. ${ }^{40}$ In trauma settings, TS is more sensitive than supine CXR and as sensitive as CT in the diagnosis of traumatic pneumothorax. ${ }^{32,41}$

Central venous cannulation is used in various hospital wards, in critically ill patients, to administer chemotherapy, hemodialysis, or total parenteral nutrition. Complications occur in more than $15 \%$ of central venous catheter (CVC) insertions. ${ }^{42}$ Incidence of pneumothorax has been reported to range from $1.3 \%$ to $1.6 \% .^{43,44}$ Postprocedure CXR is used to document correct catheter placement and to detect complications such as pneumothorax. Some authors have recommended that CXR be obtained routinely after CVC placement. ${ }^{45}$ Recently, several studies in adult population have concluded that postprocedural chest radiographs after guided insertion of CVC are unnecessary except if there are clinical indications..$^{46-50} \mathrm{In}$ a retrospective study in children, authors have found that after percutaneous fluoroscopically guided CVC insertions and in the absence of clinical indications, the use of routine postprocedural radiographs cannot be justified and are not cost effective. ${ }^{51}$

CXR is usually requested routinely after flexible bronchoscopy (FB) with transbronchial biopsy (TBB) to exclude pneumothorax, which can occur in $1 \%-6 \%$ of cases. ${ }^{52-55}$ However, in a retrospective study, 207 FB procedures were reviewed, and the authors concluded that postbronchoscopic CXR rarely provides clinically useful information or detects a complication that is not suspected clinically. ${ }^{55}$ In other retrospective study, the authors found that the combination of chest pain and the appearance of lung collapse on pre-CXR fluoroscopy is indicative of post-TBB pneumothorax, and the absence of both effectively rules out pneumothorax. ${ }^{54}$ A recent, large prospective study corroborates the findings of these previous studies, concluding that routine CXR after FB with fluoroscopically guided TBB is necessary only in patients with symptoms suggestive of pneumothorax. ${ }^{56}$

\section{Resolution}

Pneumothorax is one of the most difficult entities to diagnose using digitized radiography with lower resolutions like 1.25 line pairs per millimeter $(\mathrm{lp} / \mathrm{mm})$. The images with finer resolution $(2.5 \mathrm{lp} / \mathrm{mm})$ and unsharp mask images were superior to those with coarser resolution $(1.25 \mathrm{lp} / \mathrm{mm})$ for the diagnosis of pneumothorax. ${ }^{57}$ Nowadays, for most authors, a $2.5-1 \mathrm{p} / \mathrm{mm}$ spatial resolution is satisfactory to detect a pneumothorax.

In a study developed to compare the performance of observers using conventional radiographs, digitized radiographs (printed on laser film), and digitized radiographs $(2,048 \times 2,048 \times 12$ bits $)$ displayed on a high-resolution $(2,560 \times 2,048 \times 12$ bits $)$ gray-scale display, detectable differences were seen even at 2,048 $\times 2,048 \times 12$ bits for the detection of pneumothorax. ${ }^{58}$ In a multiobserver study, a significant reduction was shown in observer performance for the detection of pneumothorax when laser-printed radiographs or a high-resolution workstation were used rather than conventional radiographs. ${ }^{59}$

In a receiver operating characteristic (ROC) study, observer performance with digital radiographs obtained with high resolution $(4 \mathrm{~K} \times 5 \mathrm{~K})$, displayed on the workstation, was found to be significantly lower for abnormalities that contained high-frequency and low-contrast information like pneumothorax.$^{60}$ Another ROC study suggested that $2 \mathrm{~K}$ mode (standard) may be sufficient for the detection of abnormalities on CXR compared with $4 \mathrm{~K}$ mode (high quality) ${ }^{61}$ 
In order to examine the combined effects of image resolution and display luminance on observer performance, a total of 529 PA CXR were displayed on a specially constructed view box at three luminance levels and three resolutions (100- $\mu \mathrm{m}, 200-\mu \mathrm{m}$, and $400-\mu \mathrm{m}$ pixels). Only the detection of pneumothorax was significantly affected $(P<0.05)$ at the lowest $(400 \mu \mathrm{m})$ resolution level. ${ }^{62}$

Imaging interpretation using high-resolution cathoderay tube (CRT) monitors is at least as accurate as hard-copy interpretation. ${ }^{63,64}$ Active matrix liquid-crystal display (LCD) monitors have excellent spatial resolution, high uniformity, relative absence of degradation of monitor quality over time, virtual elimination of veiling glare, lack of a peripheral image distortion, and reduction of reflection associated with ambient light. ${ }^{65-67}$ In a retrospective study, ${ }^{68}$ the observer performance on CXR with 5-megapixel resolution LCD and 5-megapixel CRT monitors showed no significant statistical differences for detecting pneumothorax even under bright, ambient light conditions that simulated reading conditions of the clinical wards, emergency room, and intensive care unit. However, in this study, the detection performance was based on radiologists, not on internists or surgeons. In addition, approximately $70 \%$ of pneumothoraces had extents greater than $10 \%$ of the involved hemithorax; this large proportion might have obscured small but existing performance differences between LCD and CRT monitors.

\section{Disclosure}

The authors report no conflicts of interest in this work.

\section{References}

1. Müller NL, Fraser RS, Colman NC, Paré PD. Radiologic Diagnosis of Diseases of the Chest. Philadelphia, PA: Saunders; 2001.

2. Mettler FA. The normal chest image. Essentials of Radiology. 2nd ed. Philadelphia, PA: Saunders; 2005.

3. Carr JJ, Reed JC, Choplin RH, Pope TL Jr, Case LD. Plain and computed radiography for detecting experimentally induced pneumothorax in cadavers: implications for detection in patients. Radiology. 1992;183(1):193-199.

4. Greene R, McLoud TC, Stark P. Pneumothorax. Semin Roentgenol. 1977;12(4):313-324.

5. Beres RA, Goodman LR. Pneumothorax: detection with upright versus decubitus radiography. Radiology. 1993;186(1):19-22.

6. Bradley M, Williams C, Walshaw MJ. The value of routine expiratory chest films in the diagnosis of pneumothorax. Arch Emerg Med. 1991;8: $115-116$.

7. Schramel FM, Wagenaar M, Sutedja TG, Golding RP, Postmus PE. Diagnosis of pneumothorax not improved by additional roentgen pictures of the thorax in the expiration phase. Ned Tijdschr Geneeskd. 1995;139(3): 131-133.

8. Seow A, Kazerooni EA, Pernicano PG, Neary M. Comparison of upright inspiratory and expiratory chest radiographs for detecting pneumothoraces. AJR Am J Roentgenol. 1996;166(2):313-316.

9. Henry M, Arnold T, Harvey J. BTS guidelines for the management of spontaneous pneumothorax. Thorax. 2003;58 Suppl 2:ii39-ii52.
10. Baumann MH, Strange C, Heffner JE, et al. Management of spontaneous pneumothorax: an American College of Chest Physicians Delphi consensus statement. Chest. 2001;19(2):590-602.

11. Harrison BP, Roberts JA. Evaluating and managing pneumothorax. Emerg Med. 2005;37:18-25.

12. Rhea JT, DeLuca SA, Greene RE. Determining the size of pneumothorax in the upright patient. Radiology. 1982;144(4):733-736.

13. Collins CD, Lopez A, Mathie A, Wood V, Jackson JE, Roddie ME. Quantification of pneumothorax size on chest radiographs using interpleural distances: regression analysis based on volume measurements from helical CT. AJR Am J Roentgenol. 1995;165(5):1127-1130.

14. Kelly AM, Weldon D, Tsang AY, Graham CA. Comparison between two methods for estimating pneumothorax size from chest X-rays. Respir Med. 2006;100(8):1356-1359.

15. Aach T, Schiebel U, Spekowius G. Digital image acquisition and processing in medical x-ray imaging. J Electron Imaging. 1999;8:7-22.

16. Williams MB, Krupinski EA, Strauss KJ, et al. Digital radiography image quality: image acquisition. J Am Coll Radiol. 2007;4(6):371-388.

17. Bungay HK, Berger J, Traill ZC, Gleeson FV. Pneumothorax post CT-guided lung biopsy: a comparison between detection on chest radiographs and CT. Br J Radiol. 1999;72(864):1160-1163.

18. O'Connor AR, Morgan WE. Radiological review of pneumothorax. BMJ. 2005;330(7506):1493-1497.

19. Bourgouin P, Cousineau G, Lemire P, Hebert G. Computed tomography used to exclude pneumothorax in bullous lung disease. $J$ Can Assoc Radiol. 1985;36(4):341-342.

20. Ball CG, Hameed SM, Evans D, Kortbeek JB, Kirkpatrick AW. Occult pneumothorax in the mechanically ventilated trauma patient. Can J Surg. 2003;46(5):373-379.

21. Tocino IM, Miller MH, Frederick PR, Bahr AL, Thomas F. CT detection of occult pneumothorax in head trauma. AJR Am J Roentgenol. 1984; 143(5):987-990

22. Wall SD, Federle MP, Jeffrey RB, Brett CM. CT diagnosis of unsuspected pneumothorax after blunt abdominal trauma. AJR Am J Roentgenol. 1983;141(5):919-921.

23. Ball CG, Kirkpatrick AW, Laupland KB, et al. Incidence, risk factors, and outcomes for occult pneumothoraces in victims of major trauma. J Trauma. 2005;59(4):917-924.

24. Omert L, Yeaney WW, Protetch J. Efficacy of thoracic computerized tomography in blunt chest trauma. Am Surg. 2001;67(7):660-664.

25. Gross BH, Spizarny DL. Computed tomography of the chest in the intensive care unit. Crit Care Clin. 1994;10(2):267-275.

26. Barrios C, Tran T, Malinoski D, et al. Successful management of occult pneumothorax without tube thoracostomy despite positive pressure ventilation. Am Surg. 2008;74(10):958-961.

27. Collins J, Stern EJ. Pleura, chest wall, and diaphragm. Chest Radiology: The Essentials. 2nd ed. New York: Lippincott Williams \& Wilkins; 2008

28. Mitlehner W, Friedrich M, Dissmann W. Value of computer tomography in the detection of bullae and blebs in patients with primary spontaneous pneumothorax. Respiration. 1992;59(4):221-227.

29. Smit HJ, Wienk MA, Schreurs AJ, Schramel FM, Postmus PE. Do bullae indicate a predisposition to recurrent pneumothorax? Br J Radiol. 2000;73(868):356-359.

30. Ball CG, Kirkpatrick AW, Feliciano DV. The occult pneumothorax: what have we learned? Can J Surg. 2009;52(5):E173-E179.

31. Neff MA, Monk JS Jr, Peters K, Nikhilesh A. Detection of occult pneumothoraces on abdominal computed tomographic scans in trauma patients. J Trauma. 2000;49(2):281-285.

32. Rowan KR, Kirkpatrick AW, Liu D, Forkheim KE, Mayo JR, Nicolaou S. Traumatic pneumothorax detection with thoracic US: correlation with chest radiography and CT - initial experience. Radiology. 2002;225(1):210-214.

33. Doyle JJ, Hnatiuk OW, Torrington KG, Slade AR, Howard RS. Necessity of routine chest roentgenography after thoracentesis. Ann Intern Med. 1996;124(9):816-820.

34. Capizzi SA, Prakash UB. Chest roentgenography after outpatient thoracentesis. Mayo Clin Proc. 1998;73(10):948-950. 
35. Targhetta R, Bourgeois JM, Chavagneux R, Marty-Double C, Balmes P. Ultrasonographic approach to diagnosing hydropneumothorax. Chest. 1992;101(4):931-934.

36. Targhetta R, Bourgeois JM, Chavagneux R, et al. Ultrasonic signs of pneumothorax: preliminary work. J Clin Ultrasound. 1993;21(4): $245-250$.

37. Wernecke K, Galanski M, Peters PE, Hansen J. Pneumothorax: evaluation by ultrasound - preliminary results. J Thorac Imaging. 1987;2(2): 76-78.

38. Sartori S, Tombesi P, Trevisani L, Nielsen I, Tassinari D, Abbasciano V. Accuracy of transthoracic sonography in detection of pneumothorax after sonographically guided lung biopsy: prospective comparison with chest radiography. AJR Am J Roentgenol. 2007;188(1):37-41.

39. Sistrom CL, Reiheld CT, Gay SB, Wallace KK. Detection and estimation of the volume of pneumothorax using real-time sonography: efficacy determined by receiver operating characteristic analysis. AJR Am J Roentgenol. 1996;166(2):317-321.

40. Reissig A, Kroegel C. Sonographic diagnosis of post-interventional pneumothorax and hydropneumothorax - prospective study of 100 patients. Praxis (Bern 1994). 2006;95(16):617-624.

41. Blaivas M, Lyon M, Duggal S. A prospective comparison of supine chest radiography and bedside ultrasound for the diagnosis of traumatic pneumothorax. Acad Emerg Med. 2005;12(9):844-849.

42. McGee DC, Gould MK. Preventing complications of central venous catheterization. N Engl J Med. 2003;348(12):1123-1133.

43. Janik JE, Cothren CC, Janik JS, et al. Is a routine chest X-ray necessary for children after fluoroscopically assisted central venous access? J Pediatr Surg. 2003;38(8):1199-1202.

44. Yildizeli B, Lacin T, Batirel HF, Yuksel M. Complications and management of long-term central venous access catheters and ports. $J$ Vasc Access. 2004;5(4):174-178.

45. Abood GJ, Davis KA, Esposito TJ, Luchette FA, Gamelli RL. Comparison of routine chest radiograph versus clinician judgment to determine adequate central line placement in critically ill patients. JTrauma. 2007; 63(1):50-56.

46. Brown JR, Slomski C, Saxe AW. Is routine postoperative chest X-ray necessary after fluoroscopic-guided subclavian central venous port placement? J Am Coll Surg. 2009;208(4):517-519.

47. Burn PR, Skewes D, King DM. Role of chest radiography after the insertion of a subclavian vein catheter for ambulatory chemotherapy. Can Assoc Radiol J. 2001;52(6):392-394.

48. Chang TC, Funaki B, Szymski GX. Are routine chest radiographs necessary after image-guided placement of internal jugular central venous access devices? AJR Am J Roentgenol. 1998;170(2):335-337.

49. Lucey B, Varghese JC, Haslam P, Lee MJ. Routine chest radiographs after central line insertion: mandatory postprocedural evaluation or unnecessary waste of resources? Cardiovasc Intervent Radiol. 1999; 22(5):381-384

50. Molgaard O, Nielsen MS, Handberg BB, Jensen JM, Kjaergaard J, Juul N. Routine X-ray control of upper central venous lines: is it necessary? Acta Anaesthesiol Scand. 2004;48(6):685-689.

51. Adwan H, Gordon H, Nicholls E. Are routine chest radiographs needed after fluoroscopically guided percutaneous insertion of central venous catheters in children? J Pediatr Surg. 2008;43(2):341-343.

52. Ahmad M, Livingston DR, Golish JA, Mehta AC, Wiedemann HP. The safety of outpatient transbronchial biopsy. Chest. 1986;90(3): 403-405.

Reports in Medical Imaging

\section{Publish your work in this journal}

Reports in Medical Imaging is an international, peer-reviewed, open access journal publishing original research, reports, reviews and commentaries on all areas of medical imaging. The manuscript management system is completely online and includes a very quick and fair peer-review system, which is all easy to use.
53. Broaddus C, Dake MD, Stulbarg MS, et al. Bronchoalveolar lavage and transbronchial biopsy for the diagnosis of pulmonary infections in the acquired immunodeficiency syndrome. Ann Intern Med. 1985;102(6):747-752.

54. Frazier WD, Pope TL Jr, Findley LJ. Pneumothorax following transbronchial biopsy. Low diagnostic yield with routine chest roentgenograms. Chest. 1990;97(3):539-540.

55. Milam MG, Evins AE, Sahn SA. Immediate chest roentgenography following fiberoptic bronchoscopy. Chest. 1989;96(3):477-479.

56. Izbicki G, Shitrit D, Yarmolovsky A, et al. Is routine chest radiography after transbronchial biopsy necessary?: a prospective study of 350 cases. Chest. 2006;129(6):1561-1564.

57. Goodman LR, Foley WD, Wilson CR, Tikofsky RS, Hoffmann RG. Pneumothorax and other lung diseases: effect of altered resolution and edge enhancement on diagnosis with digitized radiographs. Radiology. 1988;167(1):83-88.

58. Cox GG, Cook LT, McMillan JH, Rosenthal SJ, Dwyer SJ III. Chest radiography: comparison of high-resolution digital displays with conventional and digital film. Radiology. 1990;176(3):771-776.

59. Slasky BS, Gur D, Good WF, et al. Receiver operating characteristic analysis of chest image interpretation with conventional, laser-printed, and high-resolution workstation images. Radiology. 1990;174(3 Pt 1): 775-780.

60. Thaete FL, Fuhrman CR, Oliver JH, et al. Digital radiography and conventional imaging of the chest: a comparison of observer performance. AJR Am J Roentgenol. 1994;162(3):575-581.

61. Kim SY, Hwang YJ, Han YH, et al. An ROC study of chest radiographs: $2 \mathrm{~K}$ vs $4 \mathrm{~K}$ high-resolution soft-copy images. J Digit Imaging. 2007; 20(4):347-351.

62. Herron JM, Bender TM, Campbell WL, Sumkin JH, Rockette HE, Gur D. Effects of luminance and resolution on observer performance with chest radiographs. Radiology. 2000;215(1):169-174.

63. Goo JM, Choi JY, Im JG, et al. Effect of monitor luminance and ambient light on observer performance in soft-copy reading of digital chest radiographs. Radiology. 2004;232(3):762-766.

64. Scharitzer M, Prokop M, Weber M, Fuchsjager M, Oschatz E, SchaeferProkop C. Detectability of catheters on bedside chest radiographs: comparison between liquid crystal display and high-resolution cathode-ray tube monitors. Radiology. 2005;234(2):611-616.

65. Hwang SA, Seo JB, Choi BK, et al. Liquid-crystal display monitors and cathode-ray tube monitors: a comparison of observer performance in the detection of small solitary pulmonary nodules. Korean J Radiol. 2003; 4(3):153-156.

66. Oschatz E, Prokop M, Scharitzer M, Weber M, Balassy C, SchaeferProkop C. Comparison of liquid crystal versus cathode ray tube display for the detection of simulated chest lesions. Eur Radiol. 2005;15(7): 1472-1476.

67. Pavlicek W, Owen JM, Peter MB. Active matrix liquid crystal displays for clinical imaging: comparison with cathode ray tube displays. J Digit Imaging. 2000;13(2 Suppl 1):155-161.

68. Park CM, Lee HJ, Goo JM, et al. Comparison of observer performance on soft-copy reading of digital chest radiographs: high resolution liquid-crystal display monitors versus cathode-ray tube monitors. Eur J Radiol. 2008;66(1):13-18.

Visit http://www.dovepress.com/testimonials.php to read real quotes from published authors. 